\title{
TEACHING ESL THROUGH CREATIVE DRAMA
}

\section{Christina Connors}

Creative Drama is an artistic form or process which employs humanistic and theatre techniques in working towards the objectives and goals within the following fields: psychoanalysis, interpersonal relations, group dynamics, education and language instruction. Creative drama in second languages provides truly authentic material, i.e., the drama of our lives and those around us, thus supplying the meaning and motivation necessary for today's communicative approach to teaching ESL.

Creative drama techniques in second language teaching/learning can be used as one small section of a regular class lesson plan, one in a series of workshops, or as in the case at Bishop's University, a credit course towards the English Proficiency Certificate.

The creative drama workshop and/or course has a theatre ensemble approach in dealing with the target language, beginning with physical warm-ups and culminating in group improvisation or the "collective creation." During the course of the workshop encounters, trust, sensitivity and awareness, as well as other humanistic exercises and games, combine with those of actor training methods and strategies, roleplay and improvisation.

The activities described below are appropriate to any level of student. Of course, it remains up to the discretion of the instructor to decide the difficulty and scope of the vocabulary and the intensity and extent of development of the theme or subject which he wishes to pursue. The order of the activities described here progresses from simple non-verbal exercises to more complex activities such as group improvisation.

\section{Activity 1: Machine (non-verbal warm-up)}

Purpose: to aid listening comprehension and encourage spontaneous response to new words and English instructions given by the animator.

Procedure: Have the participants sit cross-legged in pairs on the floor and face each other. Get the pairs attuned by having them take three deep breaths while holding hands and keeping eye contact. Next, ask one member of each pair to be a mirror and simultaneously imitate exactly what his partner does, then have them reverse roles. After the exchange, have students stand up and continue to mirror each others' movements; then, ask them to take turns creating complementary and/or opposite movements with their arms, legs and eventually whole bodies. After approximately four minutes, call FREEZE. Ask them to commit to memory their most recent or favorite pair movement, practice it and add sound to it. It is now the task of the animator to observe and engineer one 
machine out of these various moving and resonating parts. Without breaking the concentration of the pairs, slowly and through sign language, lead each pair in turn to the centre of the room, interlocking, structuring and consolidating them into one smooth-running operable machine. Let the new machine function for a while, then call FREEZE, giving a moment for the participants to eye the resulting machine. Dismantle and discuss the reactions to this exercise by asking such questions as:

What kind of machine were you?

Did you feel synchronized?

It is best to prepare a set of questions beforehand to stimulate and initiate conversation.

\section{Activity 2: Story Lines (vocabulary expansion and narration)}

Purpose: To tap the students' creativity in representing a simple object verbally and/or through body language and further develop this initial reaction to a more evolved narration.

Procedure: Have the group sit in a large circle on the floor and throw a common object such as a running shoe into the centre. Ask for volunteers to quickly rush up and transform the item and its usage into something entirely different. For example, one student may use the shoe as a telephone receiver and carry on a conversation with a friend or as an iron and proceed to press clothes. The group is encouraged to guess and interpret the actions and the nature of the object. Change objects every four times.

Another approach to this exercise is to use the first 'creation' as the opening line of a story. Each person who can come up with a follow-up line goes to the centre and says the line. If you want everyone to participate, pass the object from one to the other around the circle and have each person give a line as he receives the object.

\section{Activity 3: Rites of Spring (re presentation \& simulation)}

Purpose: To develop narrative skills further and implement them so as to experience their dynamic 'live' form.

Procedure: Still sitting in a circle, discuss with the group their understanding of the English terms: habit, rite, custom and ritual and their roles in seasonal and cultural traditions, i.e. Halloween, the Maypole, St.-JeanBaptiste, the Fleur de Lys, etc... Some brainstorming to develop vocabulary would fit in nicely here with columns for such categories as, Time of year, Object, Personage, listed on the blackboard. When the students' interest has been sufficiently aroused, divide participants into groups of five or six and using the topic "Rites of Spring," have each group prepare 
a short improvisation which they will subsequently perform. Within their groups students should first exchange ideas about their interpretation of the theme as in the following examples:

- To me it refers to those myths and legends of the gods and goddesses that are traditionally handed down to us...like the Dionysus harvest festival celebration.

- I imagine a nest full of young birds chirping for food.

Members should then pick one or more of the most original and popular ideas and organize and expand them to emcompass a story which is acted out. Participants can also be encouraged to create a tableau which is more abstract but which can incorporate sound and movement, i.e. hungry nestlings endangered by a curious pair of children while their mother is away gathering food. Allot 15 minutes for the discussion and rehearsal during which the animator should circulate among the groups to ensure that there are no problems. After the presentation, encourage the students to make comments and ask questions related to each other's skits.

To conclude, I would like to remind the animator that creative drama activities should always embody the principles of respect, sensitivity and caring in dealing with both the subtle and more energetic student displays of emotion, personality and occasionally the private territory of their inner feelings and lives. I suggest the animator seek the freedom and means within himself to proceed gently and cautiously and, most important of all, to enjoy the experience.

\section{FOOTNOTE}

The following exposition of Creative Drama activities formed part of the workshop I presented in Quebec City at the SPEAQ conference June '84. The presentation simulated a typical Creative Drama workshop and consequently active participation was required of those attending. Due to the fact that the participants were either native English speakers or possessed an equivalent mastery of the language, the workshop was geared towards an advanced level of ESL students.

\section{THE AUTHOR}

Christina Connors received a BA from Bishop's University and taught high school in Cowansville, Quebec. She has studied drama at Concordia University and is currently completing a TESL program there. She teaches at Bishop's where she has introduced and developed a Creative Drama Workshop for teaching ESL in the Continuing Education Department. 